Original Article

\title{
Comparison of Mid-Term Graft Patency between On-Pump and Off-Pump Coronary Artery Bypass Grafting
}

\author{
Tatsuya Seki, MD and Toshihito Yoshida, MD
}

\begin{abstract}
Background: Multiple studies have compared on-pump coronary artery bypass (ONCAB) grafting with off-pump coronary artery bypass (OPCAB) grafting, but the optimal surgical strategy has yet to be established. Furthermore, there is limited evidence regarding mid-term graft patency rates.

Methods: Between April 2001 and March 2014, 365 consecutive patients underwent isolated coronary artery bypass grafting (CABG; male: 75\%; mean age: $69 \pm 10$ years). After propensity-score-matched analysis, we assessed the results of 67 patients in each group (ONCAB: group A, OPCAB: group B). The mean follow-up period of graft patency and survival rate was $35 \pm 37$ months and $54 \pm 47$ months, respectively.

Results: There were no significant differences in baseline characteristics between the two groups. There was a trend for an increased number of distal anastomoses in group $B$ as compared to group A (group A vs. group B: $3.8 \pm 1.1$ vs. 4.1 $\pm 1.6, P=0.17$ ). The total graft patency rate was tend to be lower in group $\mathrm{A}$, but not statistically significant (group $\mathrm{A}$ : 156 months, 45.2\%; group $B: 96$ months, $72.6 \% ; P=0.21$ ). There was no difference for survival and major-adverse-cardiac-and-cerebrovascular-events (MACCE) free rate ( $P=0.42$ and 0.76 , respectively).

Conclusion: Propensity-score-matched analysis revealed no difference in mid-term survival rate, MACCE free rate, graft patency rates, and number of distal anastomoses between ONCAB and OPCAB groups.
\end{abstract}

Keywords: CABG, graft patency, off-pump CABG, on-pump CABG

\section{Introduction}

Although many reports comparing on-pump coronary artery bypass $(\mathrm{ONCAB})$ grafting with off-pump coronary artery bypass $(\mathrm{OPCAB})$ have been published, ${ }^{1-5)}$ the optimal surgical strategy has not been well established. ${ }^{6}$

Department of Cardiovascular Surgery, Japan Community Health Care Organization (JCHO) Hokkaido Hospital, Sapporo, Hokkaido, Japan

Received: December 20, 2016; Accepted: January 21, 2017 Corresponding author: Tatsuya Seki, MD. Department of Cardiovascular Surgery, JCHO Hokkaido Hospital, 1 jo 8 chome 3-18 Nakanoshima, Toyohira-ku, Sapporo, Hokkaido 062-8618, Japan Email: sekky48@yahoo.co.jp

(C)2017 The Editorial Committee of Annals of Thoracic and Cardiovascular Surgery. All rights reserved.
Despite the fact that many surgeons consider the offpump approach to be more technically challenging, it remains the most commonly used approach in Japan, with more than $60 \%$ of coronary artery bypass grafting (CABG) performed by OPCAB.7.8) OPCAB is superior to ONCAB because it avoids the use of cardiopulmonary bypass and aortic manipulation such as cannulation and aortic clamping; however, some studies have reported that the former is inferior in terms of patency rate and number of distal anastomoses. ${ }^{1,4)}$

Puskas et al. ${ }^{9)}$ and Magee et al. ${ }^{10)}$ reported similar graft patency rates for OPCAB and ONCAB at 30 days and 1 year, but this result has been challenged by other studies that demonstrated a lower graft patency rate for OPCAB. The Randomized On/Off Bypass (ROOBY) trial, one of the largest randomized controlled studies 


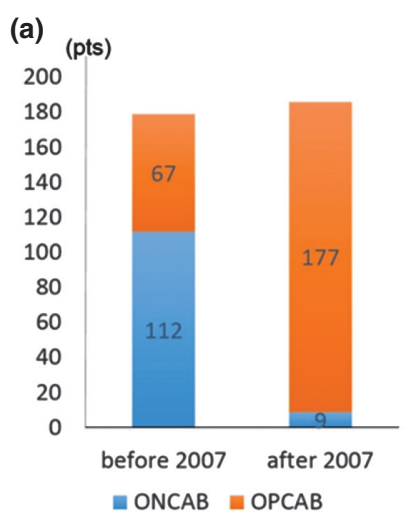

(b)

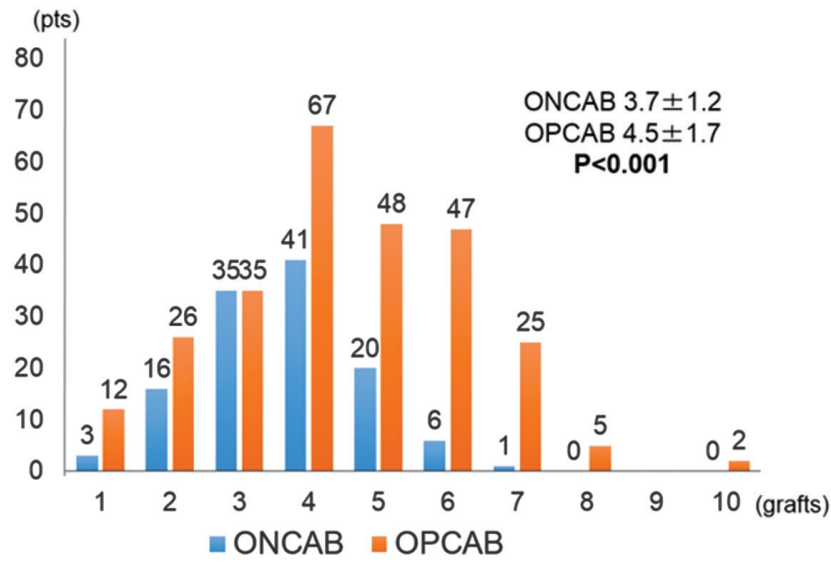

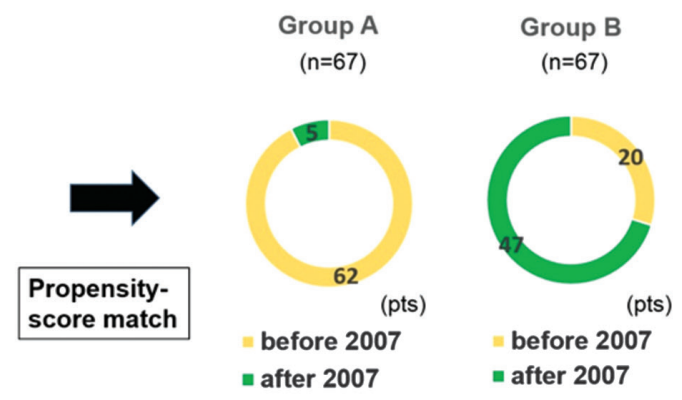

(c)

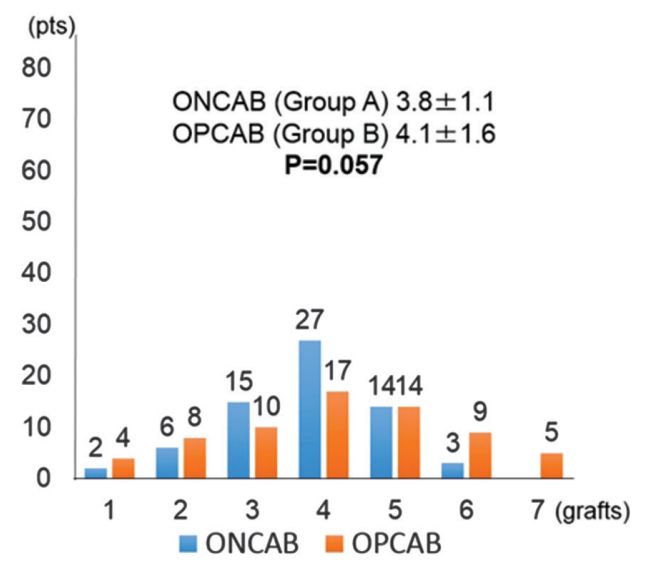

Fig. 1 (a) Trends in cardiopulmonary bypass strategies for CABG and patient details. Before 2007, the majority (67\%) of CABG was performed in on-pump (ONCAB). After 2007, OPCAB was most commonly performed. (b and c) Number of distal anastomoses of CABG before (b) and after (c) propensity-score-matched analysis. The number of distal anastomoses was higher in the off-pump CABG (OPCAB) group than in the on-pump CABG (ONCAB) group $(\mathrm{P}<0.001)$, but this difference was not significant after propensity-score-matched analysis $(\mathrm{P}=0.057)$. CABG: coronary artery bypass grafting; OPCAB: off-pump coronary artery bypass; ONCAB: on-pump coronary artery bypass.

comparing the outcomes of ONCAB and OPCAB, demonstrated greater adverse composite outcomes and patency rates with OPCAB at 1 year follow-up. ${ }^{1)}$ This finding was corroborated by the Danish On-pump Versus Off-pump Randomization Study (DOORS) randomized control trial which also showed a lower patency rate for $\mathrm{OPCAB}$ at 6 months follow-up. ${ }^{4)}$ These results were attributed to technical problems associated with OPCAB, but the studies were limited by the short duration of follow-up.

Few studies have provided long-term follow-up data of OPCAB and ONCAB grafts. Furthermore, the limited data available is from Europe and the United States, where OPCAB was used in only $20 \%$ of CABG procedures, ${ }^{11)}$ and therefore it is unclear whether these results are applicable in Japan, where a much greater proportion of $\mathrm{CABG}$ is performed using OPCAB. In this study, we used coronary computed tomography angiography
(CCTA) to compare graft patency at regular 2-yearly intervals for up to 10 years after surgery, and conducted a propensity-matched analysis adjusted for multiple risk factors.

\section{Materials and Methods}

This study was approved by the institutional review board of Japan Community Health Care Organization Hokkaido Hospital. Retrospective data were collected for 365 consecutive patients (ONCAB, $n=116$ and OPCAB, $n=249$ ) who underwent isolated CABG at our institution between April 2001 and March 2014. Following the exclusion of patients who did not undergo median sternotomy, we conducted propensity-score-matched analysis for 67 patients in each group (ONCAB: group A, OPCAB: group B). We identified 179 patients who underwent isolated CABG between April 2001 and March 
2007 (ONCAB: $\mathrm{n}=112,67 \%$ and OPCAB: $\mathrm{n}=67$, $33 \%$ ), and 186 patients who underwent isolated CABG between April 2007 and March 2014 (ONCAB: $\mathrm{n}=9$, $4 \%$ and OPCAB: $n=177,96 \%)$. Since CABG was performed mainly by off-pump in the latter half of the study, after propensity-score-matched analysis, we selected 93\% (62/67) of patients from before 2007 in group A and 70\% (47/67) of patients from after 2007 in group B (Fig. 1a). We aimed to perform traditional complete revascularization, which revascularize every stenosed branch even if there was an adjacent area of perfusion. The grafting strategy and preoperative and postoperative strategy has not been changed thorough all period.

Graft patency was assessed mainly by CCTA performed every 2 years after CABG until 10 years after surgery, even in the absence of ischemic symptoms. Cardiovascular surgeon and radiologist evaluated graft patency by CCTA. After 10 years, graft patency was assessed only in symptomatic patients. The mean followup period of patency for all patients was $35 \pm 37$, group A was $30 \pm 42$ months and for group B was $40 \pm 31$ months $(\mathrm{P}=0.93)$. The maximum follow-up period of patency was 156 months for group A and 96 months for group B. Major adverse cardiac and cerebrovascular events (MACCE) was defined as all-cause death, myocardial infarction, cerebrovascular events, and repeat revascularization. The mean follow-up period of survival and MACCE free rate for all patients was $54 \pm 47$ months, for group A was $56 \pm 55$ months and for group B was $52 \pm 38$ months $(\mathrm{P}=0.28)$. The maximum followup period of survival and MACCE rate was 168 months for group A and 132 months for group B.

\section{Surgical techniques}

All procedures were performed through a median sternotomy. In on-pump CABG, cardiopulmonary bypass was commenced through the ascending aorta and the right atrium. In on-pump arrest $\mathrm{CABG}$, the ascending aorta was cross-clamped and cardiac arrest was achieved and maintained with intermittent administration of tepid blood cardioplegic solution through the aortic root and the coronary sinus. Then, distal anastomoses were constructed during cardiac arrest using a continuous 7-0 or 8-0 polypropylene suture. In off-pump CABG, the anastomoses were constructed without cardiac arrest using intraluminal shunts and a dedicated positioner and stabilizer. The internal thoracic arteries (ITA) and radial arteries (RA) were harvested in a skeletonized fashion using electronic scalpels and/or a Harmonic scalpel (Ethicon,
Cincinnati, OH, USA). The left anterior descending coronary artery was revascularized primarily using the in situ left ITA. The diagonal branch and left circumflex coronary artery were revascularized using grafts from the right ITA, RA, or saphenous vein graft (SVG). Gastroepiploic artery (GEA) grafts were used to revascularize the right coronary artery in young patients, whereas SVGs were used for this purpose in elderly patients. The RA was not used in patients with chronic kidney disease in case of future need for hemodialysis access. Proximal anastomoses of free grafts were made on the ascending aorta using a continuous 6-0 polypropylene suture during aortic cross-clamping for those with on-pump arrest $\mathrm{CABG}$ and on the beating heart with a dedicated suture assistant device (Enclose II, Vitalitec, Plymouth, MA, USA) for those without cardiac arrest. We use heparin $100 \mathrm{U} / \mathrm{kg}$ for OPCAB and $300 \mathrm{U} / \mathrm{kg}$ for ONCAB. The target of activated whole blood clotting time was $300 \mathrm{sec}$ for $\mathrm{OPCAB}$ and $500 \mathrm{sec}$ for $\mathrm{ONCAB}$. The postoperative anticoagulant protocol for all patients consisted of heparin infusion from immediately after hemostasis until postoperative day 5 , followed by dual-antiplatelet drug therapy thereafter. CABG was mainly performed by two and one surgeons before and after 2007, respectively.

\section{Statistical analysis}

Continuous variables are presented as mean \pm standard deviation and categorical data as numbers and percentages. The Mann-Whitney $U$ test was used for the comparison of continuous values. The chi-square test or Fisher's exact test was used for the comparison of categorical data as appropriate. The survival curve, the MACCE free curve, and the graft patency curves were estimated using the Kaplan-Meier method, and betweengroup differences were compared using the log-rank test.

Propensity scores were developed based on 15 baseline characteristics. Age, sex, body surface area, smoking history, hypertension, dyslipidemia, diabetes mellitus, chronic kidney disease, hemodialysis, peripheral vascular disease, cerebral vascular disease, old myocardial infarction, chronic obstructive pulmonary disease, number of diseased vessels, and impaired left ventricular ejection fraction (LVEF) were variables used to developed propensity score. Logistic regression analysis was conducted to calculate propensity score. The C-statistics was $88.9 \%$. In all, 67 matched ONCAB and OPCAB pairs were selected from propensity matching. There was no significant difference in the preoperative characteristics of matched patients (Table 1). Statistical analysis was 
Table 1 Patients' baseline characteristics before and after propensity-score-matched analysis

\begin{tabular}{|c|c|c|c|c|c|c|}
\hline & \multicolumn{3}{|c|}{ Before PS match } & \multicolumn{3}{|c|}{ After PS match } \\
\hline & \multirow{2}{*}{ ONCAB } & \multirow{2}{*}{ OPCAB } & \multirow{3}{*}{$P$ value } & ONCAB & OPCAB & \multirow{3}{*}{$\mathrm{P}$ value } \\
\hline & & & & (Group A) & (Group B) & \\
\hline & $\mathrm{N}=116$ & $\mathrm{~N}=249$ & & $\mathrm{~N}=67$ & $\mathrm{~N}=67$ & \\
\hline Age, year & $67 \pm 10$ & $69 \pm 10$ & 0.989 & $69 \pm 10$ & $69 \pm 9$ & 0.558 \\
\hline Male, n (\%) & $92(79)$ & $200(80)$ & 0.915 & $50(75)$ & $50(75)$ & 1 \\
\hline Body surface area, $\mathrm{m}^{2}$ & $1.7 \pm 0.3$ & $1.6 \pm 0.2$ & 0.08 & $1.6 \pm 0.1$ & $1.6 \pm 0.2$ & 0.507 \\
\hline Smoking, n (\%) & $47(41)$ & $61(24)$ & 0.0018 & $20(30)$ & $19(14)$ & 0.849 \\
\hline Hypertension, n (\%) & $62(53)$ & $110(44)$ & 0.098 & $36(54)$ & $40(60)$ & 0.486 \\
\hline Diabetes mellitus, n (\%) & $56(48)$ & $145(58)$ & 0.075 & $35(52)$ & $33(49)$ & 0.729 \\
\hline Dyslipidemia, n (\%) & $49(42)$ & $112(45)$ & 0.624 & $29(43)$ & $25(37)$ & 0.481 \\
\hline COPD, n $(\%)$ & $12(10)$ & 35 (14) & 0.324 & $6(9)$ & $5(7)$ & 0.753 \\
\hline Old myocardial infarction, $\mathrm{n}(\%)$ & $33(28)$ & $44(18)$ & 0.018 & $21(31)$ & $18(27)$ & 0.568 \\
\hline Cerebral vascular disease, $\mathrm{n}(\%)$ & $36(31)$ & $59(24)$ & 0.137 & $18(27)$ & $18(27)$ & 1 \\
\hline Peripheral vascular disease, $\mathrm{n}(\%)$ & $32(28)$ & $77(31)$ & 0.517 & $16(24)$ & $20(30)$ & 0.436 \\
\hline Chronic kidney disease, $\mathrm{n}(\%)$ & $16(14)$ & $63(25)$ & 0.0129 & $13(19)$ & $12(18)$ & 0.825 \\
\hline Hemodialysis, $\mathrm{n}(\%)$ & $10(9)$ & $30(12)$ & 0.329 & $7(5)$ & $5(7)$ & 0.545 \\
\hline Impaired LVEF, n (\%) & $13(11)$ & $37(15)$ & 0.345 & $8(6)$ & $8(6)$ & 1 \\
\hline \multicolumn{7}{|l|}{ Number of diseased vessels } \\
\hline 1 vessel disease & $4(3)$ & $9(4)$ & \multirow{3}{*}{0.906} & $0(0)$ & $2(3)$ & \multirow{3}{*}{0.38} \\
\hline 2 vessel disease & $29(25)$ & $57(23)$ & & $19(28)$ & $14(21)$ & \\
\hline 3 vessel disease & $83(72)$ & $183(74)$ & & $44(66)$ & $48(72)$ & \\
\hline
\end{tabular}

Values are mean \pm SD. COPD: chronic obstructive pulmonary disease; LVEF: left ventricular ejection fraction; ONCAB: on-pump coronary artery bypass; OPCAB: off-pump coronary artery bypass; PS: propensity score

performed using JMP 12.0.1 (SAS Inc., Cary, NC, USA). The significance threshold was set at 0.05 .

\section{Results}

Table 1 summarizes the baseline characteristics of the study population before and after the propensity-scorematched analysis. Before propensity-score matching, patients in the ONCAB group had a higher rate of smoking and old myocardial infarction, whereas patients in the OPCAB group had a higher rate of chronic kidney disease. However, there were no significant differences in baseline characteristics after propensity-score matching. The incidence of hemodialysis and impaired LVEF decreased in both groups after propensity-matched analysis. The rate of triple vessel disease was approximately $70 \%$ in both groups. Table 2 shows the operative and postoperative data. There was a trend for an increased number of distal anastomoses in group B as compared to group A, but this difference was not statistically significant (group A vs. group B: $3.8 \pm 1.1$ vs. $4.1 \pm 1.6$, respectively, $\mathrm{P}=0.17$ ). Cardiopulmonary bypass time and cross-clamp time were calculated only in patients receiving extracorporeal circulation. The clinical course of three $(5 \%)$ patients in group A was complicated by postoperative stroke, but there were no cases of postoperative stroke in group $\mathrm{B}(\mathrm{P}=0.08)$. Postoperative delirium occurred in five patients $(8 \%)$ and one patient $(2 \%)$ in groups $\mathrm{A}$ and $\mathrm{B}$, respectively $(\mathrm{P}=0.095)$. There was no significant difference in the rate of reoperation due to bleeding $(\mathrm{P}=1)$, operative death $(\mathrm{P}=0.315)$, and hospital death $(\mathrm{P}=0.315)$. There was one case of operativedeath on postoperative day 7 due to non-occlusive mesenteric ischemia and multi-organ failure, and one case of hospital death at 3 months after surgery due to respiratory failure. Graft selection differed between the two groups (Group A; ITA: 35\%, SVG: 38\%, RA: 20\%, GEA: $8 \%$. Group B; ITA: 39\%, SVG: 48\%, RA: $11 \%$, GEA: $3 \%, \mathrm{P}<0.01)$. In group A, SVGs were less commonly used and RAs were more frequently used than in group B.

Figures $1 \mathbf{b}$ and $1 \mathbf{c}$ show the number of distal anastomoses before (b) and after (c) propensity-score-matched analysis. Before propensity-score-matched analysis, the mean distal anastomoses numbers were $3.7 \pm 1.2$ for group A and $4.5 \pm 1.7$ for group B $(\mathrm{P}<0.001)$. After propensity-score-matched analysis, the mean distal anastomoses numbers were $3.8 \pm 1.1$ for group A and 4.1 \pm 1.6 for group $\mathrm{B}(\mathrm{P}=0.057)$. Figure $2 \mathrm{a}$ shows the survival curve. Survival rate was not different between two 
Table 2 Operative and early postoperative data

\begin{tabular}{lccc}
\hline & $\begin{array}{c}\text { Group A } \\
(\mathrm{N}=67)\end{array}$ & $\begin{array}{c}\text { Group B } \\
(\mathrm{N}=67)\end{array}$ & P value \\
\hline Number of distal anastomoses & $3.8 \pm 1.1$ & $4.1 \pm 1.6$ & 0.17 \\
Total graft number & 251 & 271 & - \\
$\quad$ ITA, n (\%) & $87(35)$ & $105(39)$ & $<0.01$ \\
SVG, n (\%) & $94(38)$ & $130(48)$ & \\
RA, n (\%) & $51(20)$ & $29(11)$ & \\
GEA, n $(\%)$ & $19(8)$ & $8(3)$ & \\
CPB time, minutes & $189 \pm 52$ & $\mathrm{NA}$ & $\mathrm{NA}$ \\
Cross-clamp time, minutes & $129 \pm 37$ & $\mathrm{NA}$ & $\mathrm{NA}$ \\
Intubation $>48$ hour, n $(\%)$ & $9(13)$ & $4(6)$ & 0.144 \\
Stroke, $\mathrm{n}(\%)$ & $3(5)$ & $0(0)$ & 0.08 \\
Delirium, $\mathrm{n}(\%)$ & $5(8)$ & $1(2)$ & 0.095 \\
Deep sternum infection, $\mathrm{n}(\%)$ & $1(2)$ & $1(2)$ & 1 \\
Reoperation for bleeding, $\mathrm{n}(\%)$ & $1(2)$ & $1(2)$ & 1 \\
Operative death, $\mathrm{n}(\%)$ & 0 & $1(2)$ & 0.315 \\
Hospital death, $\mathrm{n}(\%)$ & $1(2)$ & 0 & 0.315 \\
\hline
\end{tabular}

CPB: cardiopulmonary bypass; GEA: gastroepiploic artery; ITA: internal thoracic artery; NA: not applicable; RA: radial artery; SVG: saphenous vein graft

(a)

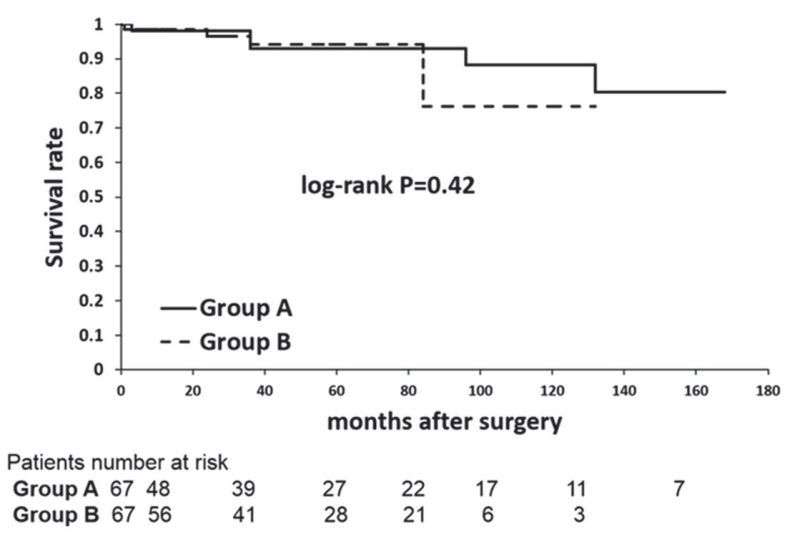

(b)

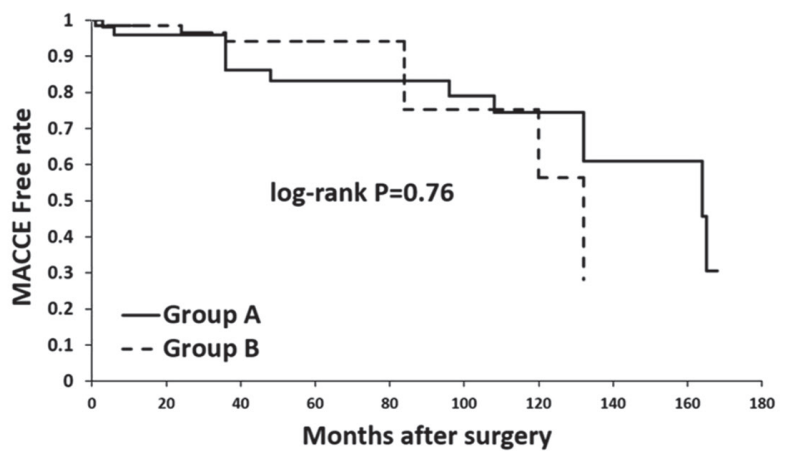

Patients number at risk

$\begin{array}{llllllll}\text { Group A } 67 & 48 & 39 & 27 & 22 & 17 & 11 & 7\end{array}$

Fig. 2 (a) The survival curve and (b) the major adverse cardiac and cerebrovascular event free curve.

groups (group A: 168 months survival rate, 80.3\%; group B: 132 months survival rate, $76.3 \%$; log-rank: $\mathrm{P}=0.42$; Fig. 2a). Figure 2b shows the MACCE free curve. MACCE free rate was not different between two groups (group A: 168 months MACCE free rate, 30.5\%; group B: 132 months MACCE free rate, 28.2\%; log-rank: $\mathrm{P}=0.76$; Fig. 2b). Figures 3a-3e show the graft patency rate. The mean follow-up period was $30 \pm 42$ months in group $\mathrm{A}$ and $40 \pm 31$ months in group $\mathrm{B}$, and the maximum follow-up period was 156 months in group A and 96 months in group B. The all-graft patency rate tended to be lower in group B compared to group A, but this difference was not statistically significant (group A: 156 months patency, $45.2 \%$; group B: 96 months patency,
72.6\%; log-rank: $\mathrm{P}=0.21$; Fig. 3a). There was no significant difference in the patency rate of ITA and RA grafts between groups (ITA graft: group A: 156 month patency, 76.3\%; group B: 96 months patency, $90.6 \%$; log-rank: $\mathrm{P}=0.88$; Fig. 3b. RA graft: group A: 156 month patency, 98.0\%; group B: 60 months patency, $100 \%$; log-rank: $\mathrm{P}=0.45$; Fig. 3c). The patency rate of $\mathrm{SVG}$ in group $\mathrm{A}$ was $0 \%$ at 156 months and in group B was $83 \%$ at 84 months (log-rank: $\mathrm{P}=0.54$ ) (Fig. 3d). GEA grafts were used infrequently in the study cohort (group A: 19 grafts, group B: 8 grafts), and the patency rate of GEA grafts was significantly lower in group B compared to group A (group A: 132 month patency, 100\%; group B: 96 months patency, 0\%; log-rank: $\mathrm{P}<0.01$; Fig. 3e). 
(a)

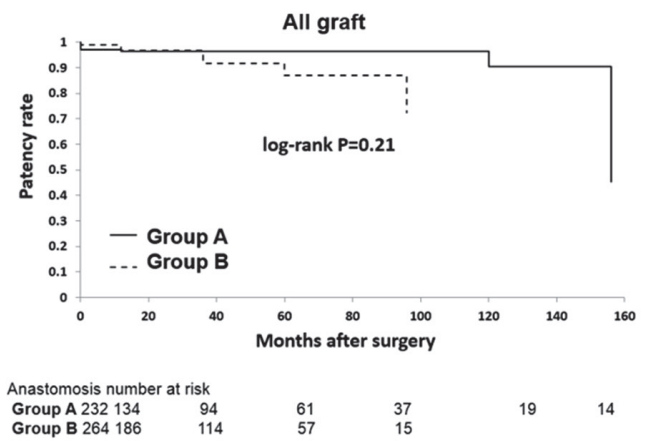

(c)

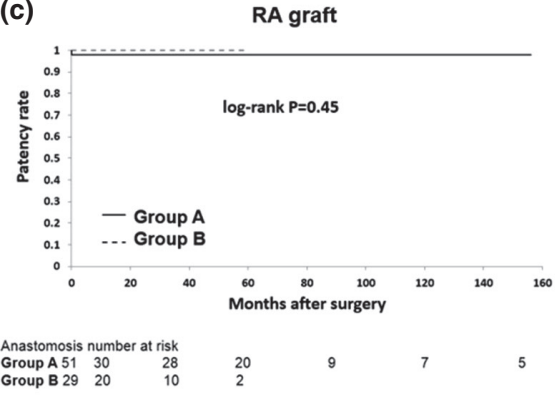

(d)

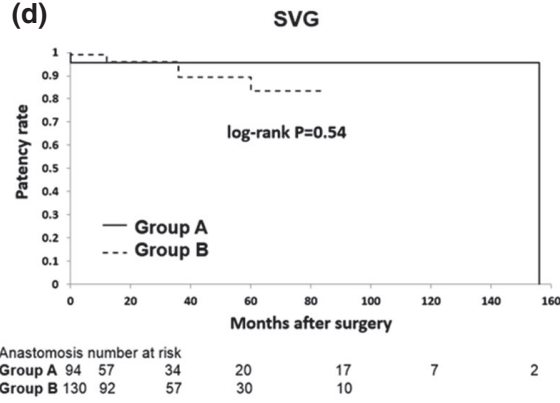

(b)

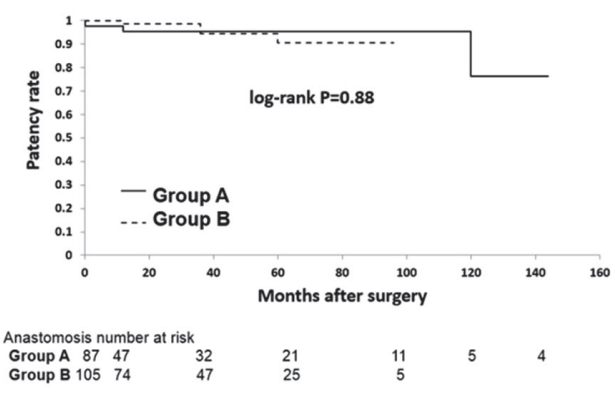

Fig. 3 Plot of time-related graft patency (or freedom from graft occlusion) for (a) all graft, (b) internal thoracic artery graft, (c) radial artery graft, (d) saphenous vein graft, (e) gastroepiploic artery graft in groups A and B. The number of grafts at each time point is listed in the figure.

\section{Discussion}

In the current study, we made two important clinical observations. First, the mid-term graft patency rate did not differ between $\mathrm{ONCAB}$ and $\mathrm{OPCAB}$ groups in a propensity-score-matched analysis. Second, there was no difference in the number of distal anastomoses between groups. However, there was a trend for an increased number of anastomoses in the OPCAB group, and this contributed to the higher use of the SVG grafts in the OPCAB group compared to that in the ONCAB group.

The ROOBY trial, one of the largest randomized controlled studies comparing the outcome of ONCAB and OPCAB, showed greater adverse composite outcomes and lower patency rates with $\mathrm{OPCAB}$ at 1-year followup. ${ }^{1)}$ However, the ROOBY trial was criticized for the fact that it had a high conversion rate (12.4\%) to cardiopulmonary bypass, which suggests that the surgeons who participated in the trial did not have sufficient expertise in OPCAB. The DOORS trial is another randomized controlled study which showed a lower patency rate with OPCAB at 6-month follow-up. ${ }^{4}$ The latter study was limited by a low rate of angiography at 6 months $(56 \%)$, as well as by a short follow-up period and surgical inexperience with OPCAB. The Japanese Off-Pump Coronary
Revascularization Investigation (JOCRI) trial is a randomized controlled study from Japan which revealed that OPCAB was the most common modality performed in $60 \%$ of CABG procedures, and this study found no differences in the early patency rate. ${ }^{5)}$ Puskas et al. ${ }^{12)}$ also reported that the 8-year patency rate did not differ between ONCAB and OPCAB. In our institute, surgeons had sufficient experience in performing $\mathrm{OPCAB}$, as evidenced by the fact that OPCAB was performed in $96 \%$ of $\mathrm{CABG}$ cases after 2007. In previous studies evaluating graft patency rates, the follow-up period was limited to less than 12 months, ${ }^{9,13-16)}$ with limited follow-up data available beyond 1 year. ${ }^{12,17)}$ In this study, we used CCTA to routinely follow-up graft patency at 2-year intervals even in asymptomatic patients, and thus provided data on midterm graft patency, which was missing in previous studies.

We found no difference in the number of distal anastomoses between the OPCAB and ONCAB groups. A meta-analysis of randomized trials showed a lower number of grafts per patient in the OPCAB group compared with ONCAB (2.6 for OPCAB and 2.8 for ONCAB) ${ }^{18)}$ However, these results were not supported by the JOCRI trial, which showed that the number of grafts per patient were similar between OPCAB and ONCAB $(3.5 \pm 1.0$ for $\mathrm{OPCAB}$ and $3.6 \pm 0.9$ for $\mathrm{ONCAB}){ }^{5)}$ 
We believe that OPCAB is a suitable technique for coronary artery revascularization, especially multiple vessel revascularization. In $\mathrm{ONCAB}$, anastomosis is performed during cardiac arrest, and therefore cardiac ischemia is inevitable. Therefore, if a surgeon is qualified to perform $\mathrm{OPCAB}$, we believe that this technique is superior to ONCAB because it eliminates the need for cardiac arrest during anastomosis. In OPCAB, we performed traditional complete revascularization, and aimed to revascularize every stenosed branch even if there was an adjacent area of perfusion, without worrying about cardiac ischemic time. We believe that this approach led to the increased number of anastomoses in OPCAB compared to ONCAB before propensity-score matching. In OPCAB, we could avoid cardiopulmonary bypass use, which was the risk factor of stroke. In this study, there was no perioperative stroke in $\mathrm{OPCAB}$ group. $\mathrm{OPCAB}$ has been indicated for high-risk patients. In one randomized control trial, Lemma et al. ${ }^{19)}$ reported that the composite primary endpoint (operative mortality, myocardial infarction, stroke, renal failure and reoperation for bleeding, and acute respiratory distress syndrome) was significantly lower for high-risk patients treated by $\mathrm{OPCAB}$ compared to ONCAB. This finding was supported by the results of Puskas ${ }^{20)}$ who reported that OPCAB was associated with a lower risk for operative mortality in highrisk patients, and that the mortality benefit increased with increasing predicted risk of mortality. Furthermore, $\mathrm{OPCAB}$ has been shown to be beneficial in high-risk patients with advanced age, ${ }^{21,22)}$ severe atheromatous aortic disease, ${ }^{23,24)}$ chronic kidney disease, ${ }^{25)}$ and left ventricular dysfunction. ${ }^{26)}$ We believe that all CABG should be performed by off-pump technique. Although good target of OPCAB was high-risk patients as mentioned above, to perform multiple revascularization for high-risk patients safely, we should perform revascularization in all patients including lower risk patients to keep surgical technique.

Conducting propensity-score-matched analysis method was the limitation in this study. Ours is not the first study to conduct a propensity-score-matched analysis comparing OPCAB and ONCAB. ${ }^{27,28)} \mathrm{We}$ found that the rate of hemodialysis and impaired LVEF decreased after propensity-score matching. This is important since previous studies have identified that high-risk patients on hemodialysis ${ }^{25)}$ and with impaired LVEF $^{26)}$ were good candidates for $\mathrm{OPCAB}$, and therefore these patients may have been partly excluded in this study. The number of distal anastomoses in the OPCAB group also decreased after propensity-score-matched analysis. The examples above highlight a limitation of using propensity-scorematched analysis.

This study has other limitations in addition to those listed above. First, the number of patients was limited. Second, this is a retrospective study which used observational data obtained from a single institution. Third, we did not control for differences in surgical expertise throughout the study period. This is important since the decision to perform off-pump versus on-pump CABG was determined by surgeons' preferences. Fourth, the follow-up periods of patency rates differed between groups due to the different time course of performing ONCAB and OPCAB procedures. Fifth, patency rate data extending beyond 10 years was limited. We routinely assessed graft patency until 10 years after surgery, following which graft patency was only evaluated in patients with ischemic symptoms. We assumed that asymptomatic patients had a patent graft, but this was not evaluated objectively.

\section{Conclusion}

In a propensity-score-matched analysis of consecutive patients who underwent $\mathrm{CABG}$ at our institution, there was no difference in mid-term survival, MACCE free and graft patency rates or number of distal anastomoses between OPCAB and ONCAB groups.

\section{Disclosure Statement}

The authors have declared that no conflict of interest exists.

\section{References}

1) Shroyer AL, Grover FL, Hattler B, et al. On-pump versus off-pump coronary-artery bypass surgery. N Engl J Med 2009; 361: 1827-37.

2) Lamy A, Devereaux PJ, Prabhakaran D, et al. Effects of off-pump and on-pump coronary-artery bypass grafting at 1 year. N Engl J Med 2013; 368: 1179-88.

3) Lamy A, Devereaux PJ, Prabhakaran D, et al. Offpump or on-pump coronary-artery bypass grafting at 30 days. N Engl J Med 2012; 366: 1489-97.

4) Houlind K, Fenger-Grøn M, Holme SJ, et al. Graft patency after off-pump coronary artery bypass surgery is inferior even with identical heparinization protocols: results from the Danish On-pump Versus Off-pump Randomization Study (DOORS). J Thorac Cardiovasc Surg 2014; 148: 1812-9.e2. 
5) Kobayashi J, Tashiro T, Ochi M, et al. Early outcome of a randomized comparison of off-pump and onpump multiple arterial coronary revascularization. Circulation 2005; 112: I338-43.

6) Polomsky M, Puskas JD. Off-pump coronary artery bypass grafting - the current state. Circ J 2012; 76: 784-90.

7) Japanese Associate for Coronary Artery Surgery (JACAS). Coronary artery surgery results 2013, in Japan. Ann Thorac Cardiovasc Surg 2014; 20: 332-4.

8) Committee for Scientific Affairs, The Japanese Association for Thoracic Surgery, Masuda M, Kuwano $\mathrm{H}$, et al. Thoracic and cardiovascular surgery in Japan during 2013: Annual report by The Japanese Association for Thoracic Surgery. Gen Thorac Cardiovasc Surg 2015; 63: 670-701.

9) Puskas JD, Williams WH, Mahoney EM, et al. Off-pump vs conventional coronary artery bypass grafting: early and 1-year graft patency, cost, and quality-of-life outcomes: a randomized trial. JAMA 2004; 291: 1841-9.

10) Magee MJ, Alexander JH, Hafley G, et al. Coronary artery bypass graft failure after on-pump and off-pump coronary artery bypass: findings from PREVENT IV. Ann Thorac Surg 2008; 85: 494-9; discussion 499-500.

11) Bakaeen FG, Shroyer AL, Gammie JS, et al. Trends in use of off-pump coronary artery bypass grafting: results from the society of thoracic surgeons adult cardiac surgery database. J Thorac Cardiovasc Surg 2014; 148: 856-3, 864.e1; discussion 863-4.

12) Puskas JD, Williams WH, O'Donnell R, et al. Offpump and on-pump coronary artery bypass grafting are associated with similar graft patency, myocardial ischemia, and freedom from reintervention: long-term follow-up of a randomized trial. Ann Thorac Surg 2011; 91: 1836-42; discussion 1842-3.

13) Lingaas PS, Hol PK, Lundblad R, et al. Clinical and radiologic outcome of off-pump coronary surgery at 12 months follow-up: a prospective randomized trial. Ann Thorac Surg 2006; 81: 2089-95.

14) Widimsky P, Straka Z, Stros P, et al. One-year coronary bypass graft patency: a randomized comparison between off-pump and on-pump surgery angiographic results of the PRAGUE-4 trial. Circulation 2004; 110: 3418-23.

15) Zhang B, Zhou J, Li H, et al. Comparison of graft patency between off-pump and on-pump coronary artery bypass grafting: an updated meta-analysis. Ann Thorac Surg 2014; 97: 1335-41.

16) Khan NE, De Souza A, Mister R, et al. A randomized comparison of off-pump and on-pump multivessel coronary-artery bypass surgery. N Engl J Med 2004; 350: $21-8$.
17) Angelini GD, Culliford L, Smith DK, et al. Effects of on- and off-pump coronary artery surgery on graft patency, survival, and health-related quality of life: long-term follow-up of 2 randomized controlled trials. J Thorac Cardiovasc Surg 2009; 137: 295-303.

18) Puskas J, Cheng D, Knight J, et al. Off-Pump versus conventional coronary artery bypass grafting: a metaanalysis and consensus statement from the 2004 ismics consensus conference. Innovations (Phila) 2005; 1: 3-27.

19) Lemma MG, Coscioni E, Tritto FP, et al. On-pump versus off-pump coronary artery bypass surgery in high-risk patients: operative results of a prospective randomized trial (on-off study). J Thorac Cardiovasc Surg 2012; 143: 625-31.

20) Puskas JD, Thourani VH, Kilgo P, et al. Off-pump coronary artery bypass disproportionately benefits highrisk patients. Ann Thorac Surg 2009; 88: 1142-7.

21) Demaria RG, Carrier M, Fortier S, et al. Reduced mortality and strokes with off-pump coronary artery bypass grafting surgery in octogenarians. Circulation 2002; 106: I5-10.

22) Panesar SS, Athanasiou T, Nair S, et al. Early outcomes in the elderly: a meta-analysis of 4921 patients undergoing coronary artery bypass graftingcomparison between off-pump and on-pump techniques. Heart 2006; 92: 1808-16.

23) Sharony R, Bizekis CS, Kanchuger M, et al. Off-pump coronary artery bypass grafting reduces mortality and stroke in patients with atheromatous aortas: a case control study. Circulation. 2003; 108: II15-20.

24) Oi K, Arai H. Stroke associated with coronary artery bypass grafting. Gen Thorac Cardiovasc Surg 2015; 63: 487-95.

25) Tashiro T, Nakamura K, Morishige N, et al. Off-pump coronary artery bypass grafting in patients with endstage renal disease on hemodialysis. J Card Surg 2002; 17: 377-82.

26) Jarral OA, Saso S, Athanasiou T. Does off-pump coronary artery bypass surgery have a beneficial effect on mortality in patients with left ventricular dysfunction? Interact Cardiovasc Thorac Surg 2012; 14: 856-64.

27) Kim JB, Yun SC, Lim JW, et al. Long-term survival following coronary artery bypass grafting: off-pump versus on-pump strategies. J Am Coll Cardiol 2014; 63: $2280-8$.

28) Liu P, Wang F, Ren S, et al. A propensity score analysis on the effect of on-pump versus off-pump coronary artery bypass grafting for patients with coronary artery disease. J Thorac Dis 2014; 6: 838-44. 